\title{
SEMICONDUCTING ORGANIC MOLECULAR MATERIALS
}

\author{
Juraj Filo - Martin Putala *
}

\begin{abstract}
This feature article gives an overview of recent advances in development of high performance molecular organic semiconductors for field-effect transistors with emphasis on the structure of molecular materials and requirements for highperformance.

K e yw or ds: organic electronics, charge carrier mobility, processability, stability
\end{abstract}

\section{INTRODUCTION}

Organic $\pi$-conjugated molecules have attracted widespread interest for potential application as semiconductors since first report in 1986 [1]. These materials offer an attractive alternative because their fabrication processes are much less complex compared to conventional inorganic technology [2]. These molecules have ability to afford high operating speed, large device densities, low cost and large area flexible circuit [3], so they can be used as "universal" materials in light-emitting diodes (OLED), organic photovoltaics (OPVs) and field-effect transistors (OFET). This review is focused on organic semiconducting materials, in particular those with low molecular weight ("small", eg nonpolymeric).

A significant improvement of charge mobility has been achieved from the initially reported $\sim 10^{-5} \mathrm{~cm}^{2} \mathrm{~V}^{-1} \mathrm{~s}^{-1}$ for polythiophene in 1986 [1] to $\sim 10^{2} \mathrm{~cm}^{2} \mathrm{~V}^{-1} \mathrm{~s}^{-1}$ for present organic films [4], and $\sim 15-40 \mathrm{~cm}^{2} \mathrm{~V}^{-1} \mathrm{~s}^{-1}$ for single crystals $[5,6]$. The high charge mobility of organic semiconductors compared to amorphous silicon indicate the great prospect of organic electronic devices for potential applications $[7,8]$.

\section{DEVICE STRUCTURES}

The physical nature of the semiconductor as well as the employed gate dielectric may require or enable different device structures that can exhibit very different transistor behavior. The most commonly used structures (in relation of the surface) are the bottom contact/top gate (BC/TG Fig. 1a), bottom contact/bottom gate (BC/BG Fig. 1b) and top contact/bottom gate (TC/BG Fig. 1c) structures. Transistors with the same components, but different geometries can show very dissimilar behavior.

One of the major differences among these device geometries arises from the position of the injecting electrodes in relation to the gate. In the bottom contact/bottom gate structure, charge is directly injected into the channel of accumulated charges at the semiconductor- dielectric interface.

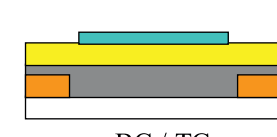

$\mathrm{BC} / \mathrm{TG}$

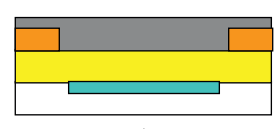

$\mathrm{BC} / \mathrm{BG}$

(b)

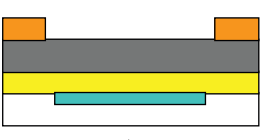

$\mathrm{TC} / \mathrm{BG}$

(c)
Fig. 1. Common field-effect transistor configurations: (a) bottom contact/top gate (BC/TG); (b) bottom contact/bottom gate $(\mathrm{BC} / \mathrm{BG}) ; \mathrm{c})$ top contact/bottom gate $(\mathrm{TC} / \mathrm{BG})$

In the other two structures, the source/drain electrodes and the channel are separated by the semiconducting layer. Thus, charges firstly have to travel through several tens of nanometers of undoped semiconductor before they reach the channel. However, in the staggered $\mathrm{BC} / \mathrm{TG}$ and TC/BG configurations, charges are injected not only from the edge of the electrode, but also from those parts of the electrode that overlap with the gate electrode, contributing to the current depending on distance from the edge [9].

\section{MATERIALS}

Organic semiconductors can be divided according to charge carrier into p-type (positive charge or holes as the major carrier), n-type (negative charge or electron as the major carrier) or ambipolar (both electrons and holes are involved as charge carriers).

\section{1 p-Type semiconductors}

\section{Oligoacenes}

Fused-ring arene compounds, oligoacenes, and their derivatives are the key candidates for organic semiconductors. Special attention has been given to pentacene Fig. 2

* Department of Organic Chemistry, Faculty of Natural Sciences, Comenius University in Bratislava, Mlynská dolina, 842 15 Bratislava, Slovakia, putala@fns.uniba.sk 
-(1). Its efficient charge transport is mainly attributed to extended $\pi$-system with strong intermolecular overlaps as well as the proper energy level of the highest occupied orbital (HOMO : $5.1 \mathrm{eV}$ ) for efficient hole injection $(\mathrm{eg}$, $\mathrm{Au}-5.1 \mathrm{eV}$ ) and transport. However, poor solubility in common organic solvents as well as its low stability in air significantly block its practical application. There is currently an interest in developing pentacene derivatives with improved solution-processability and ambient stability. Anthony and coworkers [10] synthesized a series of highly soluble and oxidatively stable functionalized pentacene compounds with ethyne group at the peri-position. It was found that the molecular packing motif strongly depended on the size and shape of substituent Fig. 2 (2a to 2 e). The best results were reported for derivative Fig. 2 (2c) because of two dimensional brick wall arrangement of pentacene molecules with strong intermolecular interaction. Thin film of $2 \mathrm{c}$ exhibited a field-effect mobility of $0.4 \mathrm{~cm}^{2} \mathrm{~V}^{-1} \mathrm{~s}^{-1}$ and $1.42 \mathrm{~cm}^{2} \mathrm{~V}^{-1} \mathrm{~s}^{-1}$ for a single crystal nanowire.

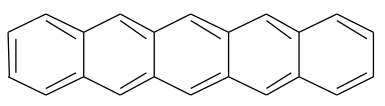

(1)

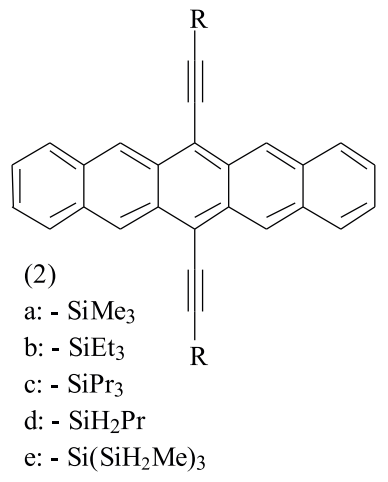

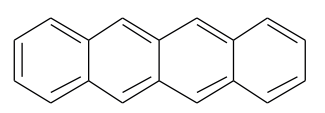

(3)

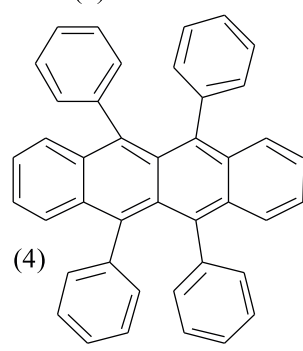

(5)

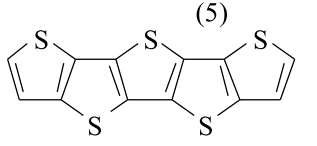

Fig. 2. (1) - pentacene, (2) - pentacene compounds,(3) tetracene , (4) - rubene , (5) - pentathienoacene

Tetracene Fig. 2 (3) have attracted attention because of better solubility and air stability. Thin film of tetracene OFETs gave field effect mobility of $0.1 \mathrm{~cm}^{2} \mathrm{~V}^{-1} \mathrm{~s}^{-1}$ [11] Rubene, see Fig. 2 (4), similar to tetracene or pentacene, is present in a herringbone motif in solid state, but its phenyl substituents could lead to major steric interaction upon a large molecular long-axis displacement (around $6.13 \AA$ ) [12], so the mobility of rubene approached $\sim 15-40 \mathrm{~cm}^{2} \mathrm{~V}^{-1} \mathrm{~s}^{-1}$. The molecule with similar shape to pentacene, having benzene rings replaced with thiophenes is called pentathienoacene, Fig. 2 (5). It was initially applied in OFETs by Xiao et al [13] in 2005. In comparison to pentacene, molecules of its thiophene analogue 5 interact together more tightly through additional intermolecular S-S contact in solid state, so that a slipped $\pi$-stacking model with a short distance of 3.52 Åwas demonstrated. Such planar and extended $\pi$ conjugation molecules gave a lower HOMO energy level of
$-5.3 \mathrm{eV}$ and a larger band gap of $3.29 \mathrm{eV}$. The best mobility achieved was $0.045 \mathrm{~cm}^{2} \mathrm{~V}^{-1} \mathrm{~s}^{-1}$ with pentathienoacene as the substrate at $80^{\circ} \mathrm{C}$.

\section{Oligothiophenes}

Another interesting class of p-type semiconductors are oligotiophenes. They represent a large group of organic materials because of unique properties of thiophene. A variety of their derivatives was prepared [14]. Well known defined are oligothiophenes, Fig. 3 (6) for $n=0,1,2,3$, $4,5,6[15]$. The interest in this class of materials has increased since the first organic transistor, build with sexithienyl (Fig. 3 (6), $n=4$ ) as an active conducting material was reported [16]. By derivatization of the backbone, various materials can be prepared. For example Meng et al [17] prepared thiophene-antracene oligomers, Fig. 3 (7) which both exhibited a bandgap around $2.8 \mathrm{eV}$, larger than of pentacene $(1.8 \mathrm{eV})$. Thin film of Fig. 3 (7b) exhibited a mobility of $0.5 \mathrm{~cm}^{2} \mathrm{~V}^{-1} \mathrm{~s}^{-1}$, which was about one order of magnitude higher than that of Fig. 3 (7a) due to the alkyl side chains improving molecular self-assembling in thin films. Ichikawa et al . [18] reported a thin film prepared from biphenyl derivative Fig. 3 (8) with mobility of $0.66 \mathrm{~cm}^{2} \mathrm{~V}^{-1} \mathrm{~s}^{-1}$.

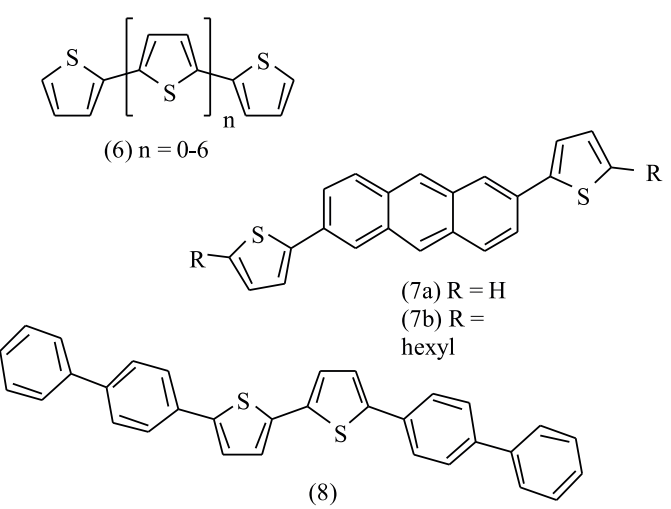

Fig. 3. (6) - oligothiophenes, (7) - thiophene-antracene oligomers, (8) - biphenyl-bithiophene compound

\section{2 n-Type semiconductors}

\section{Fluorine substituted p-type semiconductors}

An effective approach for n-type organic semiconductors is to convert known p-type materials into n-type by modifying them with strongly electronegative fluorine atoms to lower the lowest unoccupied molecular orbital (LUMO) energy levels of materials for electron injection and transport. No matter the position or the type of electron-withdrawing substitution, perfluoroarene and perfluoroalkyl both greatly affect the crystal structure, orbital energies and charge transport. 
Representative examples are in Fig. 4 (9-11). The electron mobility for Fig. 4 (10) was up to $0.5 \mathrm{~cm}^{2} \mathrm{~V}^{-1} \mathrm{~s}^{-1}$ with on/of ratio of $10^{8}$ [19]. Compound Fig. 4 (11) exhibited unprecedented solubility and stability [20], with high mobility both in solution cast (up to $0.25 \mathrm{~cm}^{2} \mathrm{~V}^{-1} \mathrm{~s}^{-1}$ ) and vapor-deposition films (up to $0.51 \mathrm{~cm}^{2} \mathrm{~V}^{-1} \mathrm{~s}^{-1}$ ).<smiles>Fc1c(F)c(F)c2c(F)c3c(F)c4c(F)c(F)c(F)c(F)c4c(F)c3c(F)c2c1F</smiles>

(9)<smiles>Fc1c(F)c(F)c(-c2ccc(-c3ccc(-c4ccc(-c5ccc(-c6c(F)c(F)c(F)c(F)c6F)s5)s4)s3)s2)c(F)c1F</smiles>

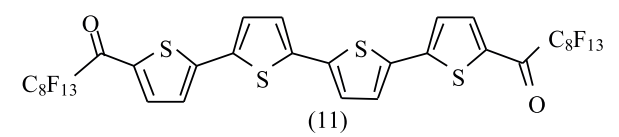

Fig. 4. (9) - perfluoropentacene, (10) - perfluorophenyl-quarterthiophene,

(11) - perfluoracyl-quarterthiophene

\section{Rylene diimides derivatives}

Arene tetracarboxylic diimides represent another group of electron-deficient $\pi$-systems suitable for producing ntype semiconductors. They exhibit relatively high electron affinities, high electron mobilities, and excellent chemical, thermal and photochemical stabilities. The widely used rylene diimides include naphthalene diimides Fig. 5 (12, NDIs) and perylene diimides Fig. 5 (13, PDIs). Among NDIs, the highest mobility in inert atmosphere was found to be $6.2 \mathrm{~cm}^{2} \mathrm{~V}^{-1} \mathrm{~s}^{-1}$ for $12 \mathrm{a}$ [21], while the highest mobility under ambient condition was found to be $0.57 \mathrm{~cm}^{2} \mathrm{~V}^{-1} \mathrm{~s}^{-1}$ for $12 \mathrm{~b}$ [22]. OFETs based on Fig. 5 (13) single crystals with poly(methyl metacrylate) (PMMA) as the gate dielectric exhibit electron mobilities of 6 and $3 \mathrm{~cm}^{2} \mathrm{~V}^{-1} \mathrm{~s}^{-1}$ in vacuum and in air, respectively, which are the highest reported for PDIs [23].

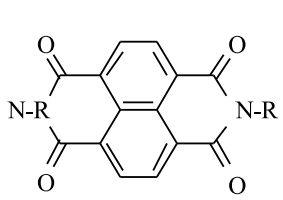

(12)
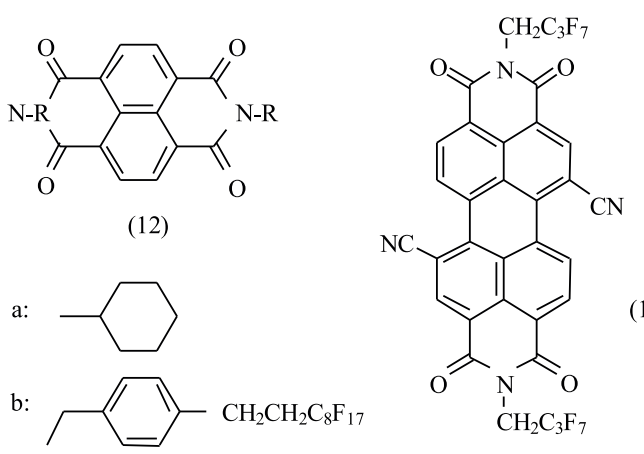

Fig. 5. ((12) - naphthalene diimides, (13) - perylene diimide

\section{Fullerene}

$\mathrm{C}_{60}$ Fig. 6 (14) is an important n-type organic semiconductor. According to theoretical calculations $\mathrm{C}_{60}$ exhibit a relatively low lying LUMO energy level that is triply degradated. Thus $\mathrm{C}_{60}$ behaves as an electron acceptor that is able to accept up to six electrons in solution. The performance of $\mathrm{C}_{60}$-based OFETs has experienced tremendous advances with electron mobilities from 0.08 to $\sim 6 \mathrm{~cm}^{2} \mathrm{~V}^{-1} \mathrm{~s}^{-1}[24]$. Despite rapid performance degradation upon exposure to air, the application of $\mathrm{C}_{60}$-based devices is challenging.

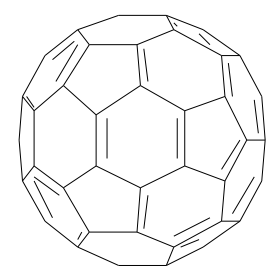

Fig. 6. (14) - fullerene

\section{MATERIAL REQUIREMENT FOR HIGH PERFORMANCE}

Efficient charge transport in molecular materials requires that the charges are able to move from molecule to molecule and are not trapped or scattered. Therefore, charge carrier mobilities are influenced by many factors including molecular packing, disorder, presence of impurities, temperature, electric field, charge-carrier density, size/molecular weight, and pressure. Some of these factors are discussed below.
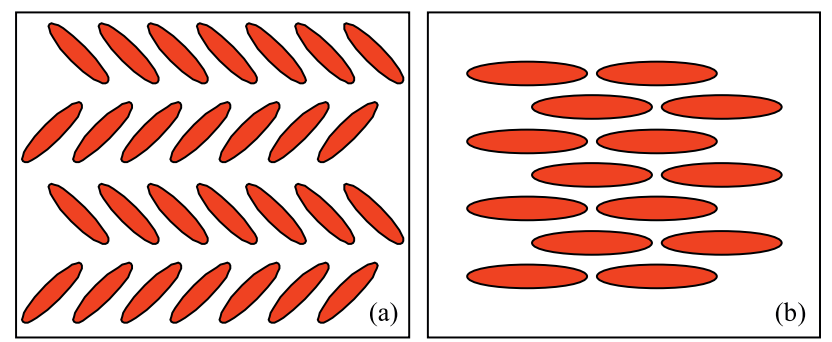

Fig. 7. Molecular packing motifs existing in organic solid states: (a) common one dimensional herringbone $\pi$-stacking motive;

(b) planar brickbone $\pi$-stacking motive providing two dimensional stacking

\subsection{Molecular packing}

The anisotropy of charge transport in single crystals point shows that the efficiency of transport is intimately related to the relative positions of the interacting molecules, and hence to crystal packing. In most instances, unsubstituted $\pi$-conjugated molecules crystallize into layered herringbone packing (Fig. 7a). Such packing gives rise to $2 \mathrm{D}$ transport within the stacked organic 
(a)

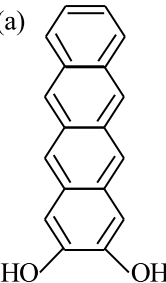

(15)

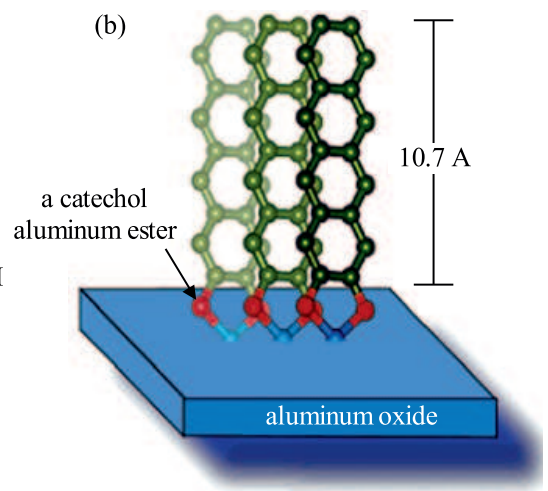

(c)

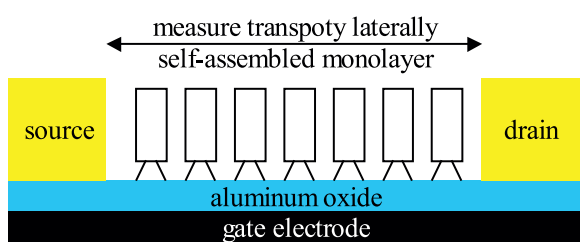

Fig. 8. (a) End functionalized tetracene 15. (b) Scheme of bonding and orientation of 15 on aluminium oxide (not intended to indicate in-plane ordering). (c) Scheme of selfassembled monolayer transistor (adapted from ref. [27])

layers [25] while transport between layers is less efficient. Therefore, the overlap degree of neighboring molecular orbitals significantly determines the mobility of charges. Molecular packing with strong intermolecular overlaps is favorable for efficient charge carrier transport and high field-effect mobility. To enhance the stacking in crystal structure, several methods are evolved [26]. Recently, extensive work has been carried out on improving the stacking by introducing polarity, increasing the $\mathrm{C} / \mathrm{H}$ ratio or adding heteroatoms to generate hydrogen bonds, halogenhalogen interaction, etc to enhance the intermolecular overlaps (such as observed in planar brickbone motive, Fig. 7b), and thus improving the charge transport properties.

Tulevski et al [27] reported attaching organic semiconductor molecules on gate oxide. They prepared tetracene derivative, Fig. 8a (15), that forms dense, upright monolayer on the surface of aluminium oxide (Fig. 8). These monolayers spontaneously self-organize into the active layer in nanoscale field-effect transistor device. With this method devices with highly organized monolayer that have

source-drain distance less than $100 \mathrm{~nm}$ can be prepared.

Another approach is to anchore the semiconductor molecules on silicon surface through phosponate bond to create a self-assembled layer. This method was demonstrated for octadecylphosphonate and $\alpha$-quarterthiophene-2-ylphosphonate [28]. Growing an organophoshonate film on $\mathrm{SiO}_{2} / \mathrm{Si}$ by self-assembly is straightforward process: the substrate is held vertically in solution of corresponding organo-phosphonic acid below its critical micelle concentration (CMC) [29], and the solvent is allowed to evaporate slowly. As the meniscus slowly traverses the substrate is transferred to the surface in inverse analogy

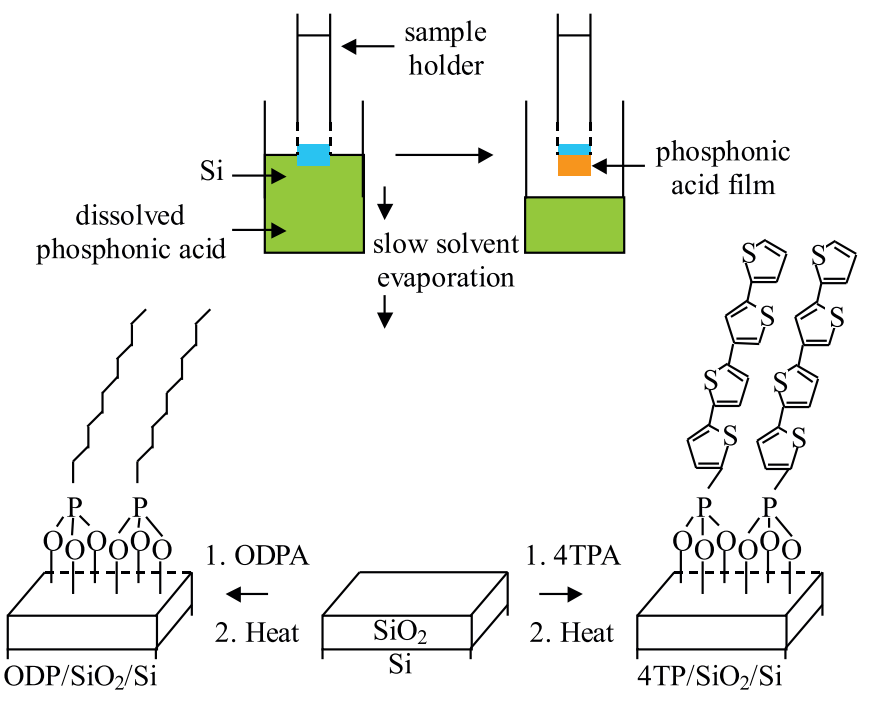

Fig. 9. The "tethering by aggregation and grow" setup and chemical reactions (adapted from ref. [31])

to Langmuir-Blodgett method (Fig. 9), but without application of pressure [30].

Another approach to improve the charge injecton is to interpose an appropriately oriented dipole layer between contact and semiconductor. Marmont et al. [31] reported a preparation of OFET consisting of pentacene and gold as a drain/source contacts. The contacts were modified with self assembled monolayers (SAMs) made of alkane or fluorinated alkane thiols. They observed decrease/increase of the mobility depending on the SAM (Tab. 1). The molecules of pentacene are preferentially oriented perpendicular to the electrode. Work function of gold is reduced with an alkane chain, while it is increased in the case of fluorinated molecule, in good agreement with the direction of the respective molecules.

\subsection{Tuning energy gap and energy alignment}

The electronic structure of molecules not only plays an important role for charge injection and transport in organic semiconductors, but is crucial for its environmental stability too. Hence, it is important to design molecules with consideration of molecular energy gaps and levels. For p-type materials, the HOMO levels are typically $4.9-5.5 \mathrm{eV}$, while for n-type materials the LUMO levels are normally $34 \mathrm{eV}$. A simple example to tune the energy gap and levels of organic semiconductors is to use star organic semiconductors as the parent cores to rationally modify or structurally reorganize them. For example, judicious choice of appropriate conjugation units (such as acenes or oligothiophene cores) and incorporation of some weakly electron-donating groups (such as double/triple carbon bond or chalcogen atoms) and side chains in the molecule serve to lower the HOMO energy 


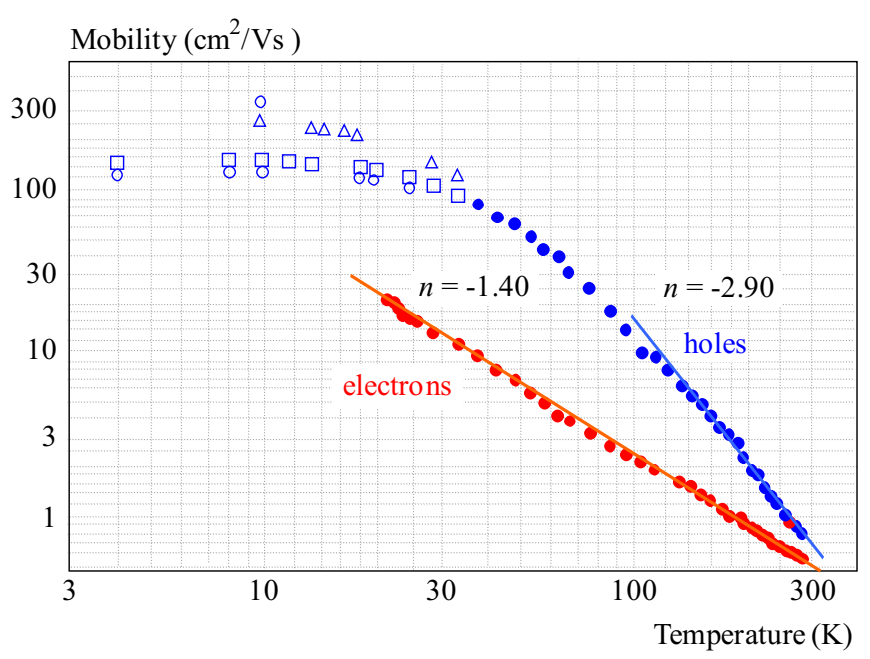

Fig. 10. Log-log plot of electron and hole mobilities in ultrapure naphthalene as a function of temperature. The applied electric field is approximately paralel to crystalographic direction (adapted from ref [40])

Table 1. Saturation mobility of bare and SAM-modified pentacenetransistor (DT-decanethiol; PFDT-1,1,2,2-H-perfluorodecanethiol; PFHT-1,1,2,2-H-perfluorohexane-thiol)

\begin{tabular}{lcccc}
\hline SAM & None & DT & PFDT & PFHT \\
\hline Mobility $\left(\mathrm{cm}^{2} \mathrm{~V}^{-1} \mathrm{~s}^{-1}\right)$ & 0.040 & 0.016 & 0.065 & 0.105 \\
\hline
\end{tabular}

level, as well as strengthen molecular interactions, resulting in many extraordinarily high performance and air stable p-type organic semi-conductors [17,32-35]. Introducing strong electron-withdrawing groups to stabilize the organic anions against oxygen and water is another effective approach for highly stable n-type semiconductors $[23,36,37]$.

\subsection{Purity}

Impurities in organic semiconductors introduced through the complex synthesis process or defects in the molecular structure itself can severely result in poor fieldeffect performance by forming a large amount of charge trapping sites in the active layer or acting as dopants for semiconducting materials. Currently, two approaches have been widely used to obtain highly pure materials, (i) simplifying synthetic routes, optimizing synthetic sequences, or beginning with purified starting materials [38], (ii) purifying products many times, such as by gradient sublimation, etc. [39]. These methods work effectively for small molecules.

\subsection{Temperature}

Temperature dependence is markedly different in single crystals and in disordered materials. In single crystal, the hole and electron mobility generally decrease with temperature according to a power law evolution: $m \div T^{-n}$ [40]. This is illustrated in Fig. 10 for the case of electron and hole transport along a crystal axis direction of naphthalene. Similar evolution is observed along specific direction for a large number of single crystals; the main difference lies in the value of $n$, which typically varies between 0.5 and 3 .

In highly disordered systems, transport generally proceeds via hopping and is thermally activated. Higher temperatures improve transport by providing the requirement to overcome the barriers created by energy disorder.

\subsection{Other factors}

Many studies have also addressed the influence of film morphology on charge transport and OFET performances. In thin films, grain boundaries are the key to carrier transport. As intermolecular charge hopping across the grain boundaries, or through disorder domains, is not as efficient as that within ordered domains. Increasing grain sizes with good film continuity is a promising approach to improve charge transport and mobility. Interface quality and compatibility greatly influence the grain size and boundaries. Hence, numerous methods, including optimizing interface quality[7,41] film treatments (such as thermal or solvent annealing) $[42,43]$ and other strategies $[44,45]$ have been studied recently to control the morphology of organic thin films. For example, it is effective to tune the surface energy by self-assembled monolayers (SAMs) prior to the deposition of organic semiconductors to improve the interface compatibility. Generally, a high surface energy leads to larger grain sizes and therefore results in high device performance with significantly increased mobility and reduced subthreshold slopes.

\section{CONCLUSIONS}

$\pi$-Conjugated molecular organic materials with semiconductor properties, overviewed in this paper, represent promising functional materials for high performance fieldeffect transistors. They exhibit high charge carrier mobility and on/off ratio. In the same time, they are easily tun- 
able by structural modifications and offer advantageous processability. However, stability issues should be considered.

\section{Acknowledgement}

This publication is the result of the project implementation "Center of excellence for design, preparation and diagnostics of nanostructures for electronics and photonics (NanoNet)" supported by the Research \& Development Operational Programme funded by the European Regional Development Fund.

\section{REFERENCES}

[1] TSUMURA, A.-KOEZUKA, H.-AMdO, T. : Macromolecular Electronic Device - Field-Effect Transistor with a Polythiophene Thin-Film, Appl. Phys. Lett. 49 (1986), 1210-1212.

[2] BRUSSO, J. L.-HIRST, O. D.-DADVAND, A.-GANESAN, S.-CICOIRA, F.-ROBERTSON, C. M.-OAKLEY, R. T.ROSEI, F.-PEREPICHKA, D. F.: Two-Dimensional Structural Motif in Thienoacene Semiconductors: Synthesis, Structure, and Properties of Tetrathienoanthracene Isomers, Chem. Mater. 20 (2008), 2484-2494 and citations reported therein.

[3] HE, Y.-CHEN, Z. H.-ZHENG, Y.-NEWMAN, C.-QUINN, J. R.-DOTZ, F.-KASTLER, M.-FACCHETTI, A.: A High-Mobility Electron-Transporting Polymer for Printed Transistors, Nature 457 (2009), 679-686.

[4] LI, L.-TANG, Q.-LI, H.-YANG, X.-HU, W.-SONG, Y.-SHUAI, Z.-XU, W.-LIU, Y.-ZHU, D.: An Ultra Closely $\pi$-Stacked Organic Semiconductor for High Performance Field-Effect Transistors, Adv. Mater. 19 (2007), 2613-2617.

[5] TAKEYA, Y.-YAMAGISHI, M.-TOMINARI, Y.-HIRAHARA, R.-NAKAZAWA, Y.-NISHIKAWA, T.-KAWASE, T.-SHIMODA-OGAWA, S.: Very High Mobility Organic Single Crystal Transistors with In-Crystal Conduction Channels, Appl. Phys. Lett. 90 (2007), 102120.

[6] JURChESCU, O. D.-POPINCIUS, M.-VAN WEES, B. J.-PALSTRA, T. T. M.: Interface-Controlled, High-Mobility Organic Transistors Adv. Mater..

[7] DONG, H.-WANG, C.-HU, W.: High Performance Organic Semiconductors for Field-Effect Transistors, Chem. Commun. 46 (2010), 5211-5222.

[8] ZAUMSEIL, J.-SIRRINGHAUS, H. : Electron and Ambipolar Transport in Organic Field-Effect Transistors, Chem. Rev. 107 (2007), 1297-1323 and citations reported therein.

[9] STREet, R. A.-SALEO, A.: Contact Effects in Polymer Transistors, Appl. Phys. Lett. 81 (2002), 2887-2890.

[10] ANTHONY, J. E.-BROOKS, J. S.-EATON, D. L.-PARKIN, S. R.: Functionalized Pentacene: Improved Electronic Properties from Control of Solid-State Order, J. Am. Chem. Soc. 123 (2001), 9482.

[11] GOLDMAN, C.-HAAS, S.-KRELLNER, C.-PERNSTICH, K. P.-GUNDLACH, D. J.-BATTLOG, B.: Hole Mobility in Organic Single Crystals Measured by a "Flip-Crystal" Field-Effect Technique, J. Appl. Phys. 96 (2004), 2080-2086.

[12] DA SILVA FILHO, D. A.-KIM, E.-G.-BRD́AS, J.-L. : Transport Properties in the Rubrene Crystal: Electronic Coupling and Vibrational Reorganization Energy, Adv. Mater 17 (2005), 1072-1076.

[13] XIAO, K.-LIU, Y.-QI, T.-ZHANG, W.-WANG, F.GAO, J.-QUI, W.-MA, Y.-CIU, G.-CHEN, S.-ZHAN, X.-YU, G.-QIN, J.-HU, W.-ZHU, D. J. :: A Highly $\pi$-Stacked Organic Semiconductor for Field-Effect Transistors Based on Linearly Condensed Pentathienoacene, J. Am. Chem. Soc. 127 (2005), 13281-13286..
[14] MiShrA, A.-MA, C.-Q.-BÄUERLE, P.: Functional Oligothiophenes: Molecular Design for Multidimensional Nanoarchitectures and Their Applications, Chem. Rev. 109 (2009), 1141-1276.

[15] WOLFER, P.-MÜLLER, C.-SMITH, P., BAKLAR, M. A.STINGELIN-STUTZMAN, N. : $\alpha$-Quaterthiophene-Polyethylene Blends: Phase Behaviour and Electronic Properties, Synth. Met. 157 (2007), 827-833 and citations reported therein.

16] GARNIER, F.-HAJLAOUI, R.-YASSAR, A.-SRIVASTAVA, P. : All-Polymer Field-Effect Transistor Realized by Printing Techniques, Science 265 (1994), 1684-1686.

[17] MENG, H.-SUN, F.-GOLDFINGER, M. B.-JAYCOX, G. D.-LI, Z.-MARSHALL, W. J.-BLACKMAN, G. S.: HighPerformance, Stable Organic Thin-Film Field-Effect Transistors Based on Bis-5-alkylthiophen-2-yl-2,6-anthracene Semiconductors, J. Am. Chem. Soc. 127 (2005), 2406-2407.

18] ICHIKAWA, M.-YANAGI, H.-SHIMIZU, Y.-HOTTA, S. -SUGANUMA, N.-KOYAMA, T.-TANIGUCHI, Y.: Organic Field-Effect Transistors made of Epitaxially Grown Crystals of a Thiophene/Phenylene Co-Oligomer, Adv. Mater. 14 (2002), 1272-1275.

19] YOON, M.-H.-FACCHETTI, A.-STERN, C. E.-MARKS, T. J. : Fluorocarbon-Modified Organic Semiconductors: Molecular Architecture, Electronic, and Crystal Structure Tuning of Arene- versus Fluoroarene-Thiophene Oligomer Thin-Film Properties, J. Am. Chem. Soc. 128 (2006), 5792-5801.

20] Letizia, J. A.-FACChetTi, A.-STERN, C. E.-RATNER, M. A.-MARKS, T. J.: High Electron Mobility in Solution-Cast and Vapor-Deposited Phenacyl-QuaterthiopheneBased Field- Effect Transistors: Toward N-Type Polythiophenes, J. Am. Chem. Soc. 127 (2005), 13476-13477.

21] SHUKLA, D.-NELSON, S. F.-FREEMAN, D. C.-RAJESWARAN, M.-AHEARN, W. G.-MEYER, D. M.-CAREY, J. T. : Thin-Film Morphology Control in Naphthalene-DiimideBased Semiconductors: High Mobility n-Type Semiconductor for Organic Thin-Film Transistors, Chem. Mater. 20 (2008), 7486-7491.

22] SEE, K. C.-LANDIS, C.-SARJEANT, A.-KATZ, H. E. : Easily Synthesized, Highly Crystalline Naphthalenetetracarboxylic Diimide Semiconductors with High Electron Mobility in Air, Chem. Mater. 20 (2008), 3609-3616.

[23] MOLINARI, A. S.-ALVES, H.-CHEN, Z.-FACHETTI, A.-MORPURGO, A. F. : High Electron Mobility in Vacuum and Ambient for PDIF-CN2 Single-Crystal Transistors, J. Am. Chem. Soc. 131 (2009), 2462-2463.

24] ANTHOPOULOS, T. D.-SINGH, B.-MARJANOVIC, N.SACRIFTCI, N. S.-MONTAIGNE, A.-SITTER, H.-CÖLLE, M.-DE LEEUW, D. M.: High Performance n-Channel Organic Field-Effect Transistors and Ring Oscillators Based on C60 Fullerene Films, Appl. Phys. Lett. 89 (2006), 213504.

25] HOROVITZ, G. : Organic Field-Effect Transistors, Adv. Mater. 10 (1998), 365-377.

[26] SMITH, R. K.-LEWIS, P. A.-WEISS, P. S.: Patterning Self-Assembled Monolayers, Prog. Surf. Sci. 75 (2004), 1-68.

27] TUlEVski, G. S.-MIAO, Q.-FUKUTO, M.-ABRAM, R. -OCKO, B.-PINDAK, R.-STEIGERWALD, M. L.-KAGAN, C. R.-NUCKOLLS, C.: Attaching Organic Semiconductors to Gate Oxides: in Situ Assembly of Monolayer Field Effect Transistors, J. Am. Chem. Soc. 126 (2004), 15048-15050..

28] HANSON, E. L.-SCHWARTZ, J.-NICKEL, B.-KOCH, N.-DANISMAN, M. F.: Bonding Self-Assembled, Compact Organophosphonate Monolayers to the Native Oxide Surface of Silicon, J. Am. Chem. Soc. 125 (2003), 16074-16080.

29] NEVES, B. R. A.-SALMON, M. E.-RUSSEL, P. E.-TROUGHTON, E. B., jr.: Spread Coating of OPA on Mica: From Multilayers to Self-Assembled Monolayers, Langmuir 17 (2001), 8193-8198. 
[30] GAINES, G. L., jr.: Insoluble Monolayers at Liquid-Gas Interfaces, Interscience Publisher, New York, 1966.

[31] MARMONT, P.-BATTAGLINI, N.-LANG, P.-HOROWITZ, G.-HWANG, J.-KAHN, A.-AMATO, C.-CALAS, P.: Improving Charge Injection in Organic Thin-Film Transistors with Thiol-Based Self-Assembled Monolayers, Org. Electron. 9 (2008), 419-424.

[32] IZAWA, T.-MIYAZAKI, E.-TAKIMIYA, K. : Molecular Ordering of High-Performance Soluble Molecular Semiconductors and Re-Evaluation of Their Field-Effect Transistor Characteristics, Adv. Mater. 20 (2008), 3388-3392.

[33] YAMAMOTO, T.-TAKIMIYA, K. : Facile Synthesis of Highly $\pi$-Extended Heteroarenes, Dinaphtho[2,3-b:2,3-f] chalcogenopheno [3,2-b]chalcogenophenes, and Their Application to FieldEffect Transistors, J. Am. Chem. Soc. 129 (2007), 2224-2225.

[34] SUBRAMANIAN, S.-PARK, S. K.-PARKIN, S. R.-PODZOROV, V.-JACKSON, T. N.-ANTHONY, J. E.: Chromophore Fluorination Enhances Crystallization and Stability of Soluble Anthradithiophene Semiconductors, J. Am. Chem. Soc. 130 (2008), 2706-2707.

[35] MENG, H.-SUN, F.-GOLDFInGER, M. B.-GAO, F.LONDONO, D. J.-MARSHAL, W. J.-BLACKMAN, G. S.-DOBBS, K. D.-KEYS, D. E. : 2,6-Bis[2-(4-pentylphenyl) vinyl]anthracene: A Stable and High Charge Mobility Organic Semiconductor with Densely Packed Crystal Structure, J. Am. Chem. Soc. 128 (2006), 9304-9305.

[36] SCHMIDT, R.-HAK OH, J.-SUN, Y.-S.-DEPPISCH, M.KRAUSE, A.-M.-RADACKI, K.-BRAUNSCHWEIG, H.KONEMANN, M.-ERK, P.-BAO, Z.-WÜRTNERF. : HighPerformance Air-Stable n-Channel Organic Thin Film Transistors Based on Halogenated Perylene Bisimide Semiconductors, J. Am. Chem. Soc. 131 (2009), 6215-6228.

[37] GSÄNGER, M.-HAK OH, J.-KÖNEMANN, M.-WÖLFGANG HÖFFKEN, H.-KRAUSE, A.-M.-BAO, Z.-WÜRTHER, F. : A Crystal-Engineered Hydrogen-Bonded Octachloroperylene Diimide with a Twisted Core: An n-Channel Organic Semiconductor, Angew. Chem. Int. Ed. 49 (2010), 740-743.

[38] KATZ, H. E.-BAO, Z.-GILAT, S. L.: Synthetic Chemistry for Ultrapure, Processable, and High-Mobility Organic Transistor Semiconductors, Acc. Chem. Res. 34 (2001), 359-369.

[39] ZEIS, R. : Single Crystal Field-Effect Transistors based on Layered Semiconductors, PhD Thesis, Universität Konstantz, Germany, 2005.

[40] WARTA, W.-KARL, N.: Hot Holes in naphthalene: High, Electric-Field-Dependent Mobilities,, Phys. Rev. B 32 (1985), $1172-1182$.

[41] KLINE, R. J.-DELONGCHAMP, D. M.-FISCHER, D. A.LIN, E. K.-HEENEY, MCCULLOCH, I.-TONEY, M. F.:
Significant Dependence of Morphology and Charge Carrier Mobility on Substrate Surface Chemistry in high Performance Polythiophene Semiconductor Films, Appl. Phys. Lett. 90 (2007), 062117.

42] MCCULLOCH, I.-HEENEY, M.-BAILEY, C.-GENIVICIUS, K.-MACDONALD, I.-SHKUNOV, M.-SPARROWE, D.-TIERNEY, S.-WAGNER, R.-ZHANG, W. M.CHARBYNIC, M. L.-KLINE, R. J.-MCGEHEE, M. D.TONEY, M. F.: Liquid-Crystalline Semiconducting Polymers with High Charge-Carrier Mobility, Nat. Mater. 5 (2006), 328-333.

[43] DICKEY, K. C.-AnTHONY, J. E.-LOO, Y.-L.: Improving Organic Thin-Film Transistor Performance through Solvent-Vapor Annealing of Solution-Processable Triethylsilylethynyl Anthradithiophene, Adv. Mater. 18 (2006), 1721-1726.

44] TSAO, H. N.-CHO, D.-ANDREASEN, J. W.-ROUHANIPOUR, A.-BREIBY, D. W.-PISULA, W.-MÜLLEN, K. The Influence of Morphology on High-Performance Polymer Field-Effect Transistors, Adv. Mater. 21 (2009), 209-212.

[45] ZEN, A.-PFLAUM, J.-HIRSCHMANN, S.-ZHUANG, W. - JAISER, F.-ASAWAPIROM, U.-RABE, J. P.-SCHERF, U.-NEHER, D.: Effect of Molecular Weight and Annealing of Poly(3-hexylthiophene)s on the Performance of Organic Field-Effect Transistors, Adv. Func. Mater. 14 (2004), 757-764.

Received 28 June 2010

Juraj Filo (MSc) was born in Liptovský Mikuláš, Slovakia in 1985. He graduated from Faculty of Natural Sciences, Comenius University in Bratislava, in Organic Chemistry, 2009. At present he is as PhD student at the Department of Organic Chemistry.

Martin Putala (Assoc Prof, RNDr, PhD) was born in Bratislava, Slovakia in 1965. He graduated from Faculty of Natural Sciences, Comenius University in Bratislava, in Inorganic Chemistry and Organic Chemistry, 1988 and received $\mathrm{PhD}$ degree at Faculty of Chemistry, Moscow State University, in organoelement chemistry branch, 1993. Since then he has been with Faculty of Natural Sciences, Comenius University in Bratislava, Department of Organic Chemistry. He also worked at University of Geneva and University of Regensburg. In 2002 he was appointed Associate Professor. He is scientifically active in the areas of synthesis of chiral aromatic compounds and their application in stereoselective catalysis, supramolecular and materials chemistry, including electronics and photoelectronics. 